\title{
Optimization of the Thermal Spraying Process DEPENDING ON THE SURFACE ROUGHNESS
}

\author{
Tomas Zatloukal, Miroslav Gombar, Jaroslava Fulemova, \\ Jan Rehor \& Michal Povolny
}
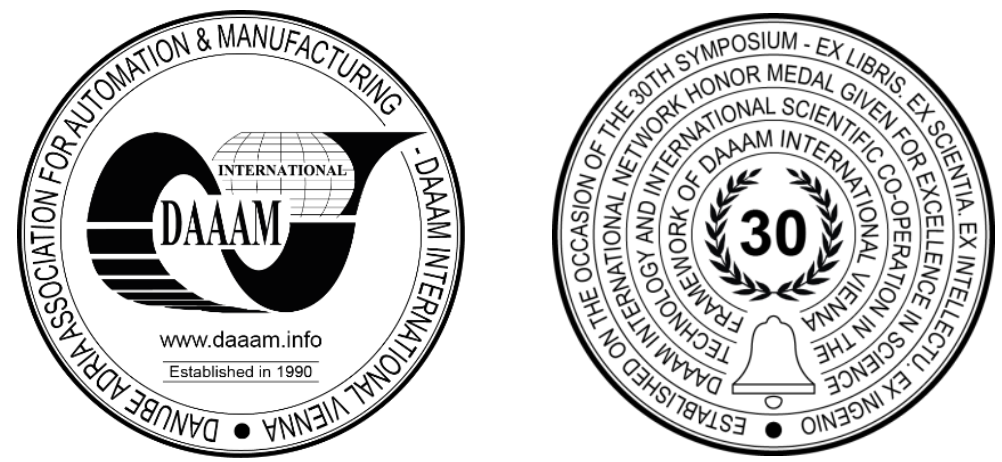

This Publication has to be referred as: Zatloukal, T[omas]; Gombar, M[iroslav]; Fulemova, J[aroslava]; Rehor, J[an] \& Povolny, M[ichal] (2019). Optimization of the Thermal Spraying Process Depending on the Surface Roughness, Proceedings of the 30th DAAAM International Symposium, pp.1026-1033, B. Katalinic (Ed.), Published by DAAAM International, ISBN 978-3-902734-22-8, ISSN 1726-9679, Vienna, Austria

DOI: $10.2507 / 30$ th.daaam.proceedings.143

\begin{abstract}
Nowadays, the requirements for the properties of machine parts are increasing. With this trend, the application of thermal spray coatings is also increasing in practice, with the aim of increasing resistance towards mechanical wear, corrosion, and oxidation, even at elevated temperatures. Research has been conducted in the field of machining for several years to increase efficiency in the machining process. This article is focused on the machinability of chromium - cobalt alloy called Stellite 6 produced using a high velocity oxygen fuel method (HVOF). The technology chosen was the shaping process. A total of 24 semi-finished products were machined under different cutting conditions. The results of the experiment are roughness values depending on the cutting speed, cutting depth and rake angle setting. Several graphs were created using statistical analysis showing optimal cutting conditions to obtain the best roughness values during the cutting process.
\end{abstract}

Keywords: Thermal Spray; Stellite 6; HVOF; Surface Roughness; Machining; Cutting Conditions

\section{Introduction}

At present, the requirements for materials used in the engineering industry are increasing. With this trend, the application of thermal spraying is also increasing. Their greatest advantage is increased resistance to mechanical wear, chemical environment, corrosion, and oxidation, even at elevated temperatures. There are several areas in which thermal spraying can be encountered. For example, general engineering where these coatings are applied to pumping and hydraulic technology to increase wear and corrosion resistance. They are used in the power industry as a thermal barrier, protection against cavitation, erosion and corrosion. Last but not least, thermal spraying is widely used in the automotive and aerospace industries, where it is applied to internal combustion engine parts to increase wear resistance and resistance to high temperatures. [1], [8], [9]

At the same time, in the case of parts of internal combustion engines, pumping equipment or injection molds, the surface roughness value should be kept to a minimum. As the roughness increases, the risk of crack formation and it's spreading increases. This also deteriorates the accuracy, durability and last but not least the corrosion resistance of the component. After application to the base material, the thermal spray has a roughness value of approx. $\mathrm{Ra}=6 \mu \mathrm{m}$. [1], [5], [9] 
Grinding technology is currently used to reduce the roughness of the applied coating. In order to increase efficiency in the machining process, research has been carried out for several years to replace not very productive grinding technology with machining technology with defined cutting edge geometry (e.g. turning, milling, shaping). [1], [7], [11]

This work dealt with machinability thermal spray Stellite 6. The main objective of this work was to replace the grinding technology for more productive machining technology with defined cutting geometry. The main advantage of this change is the shortening of production times and thus the increase of productivity and also the change of residual stresses from tensile to compressive. [7], [11]

Currently, there are several studies dealing with the machinability of thermal spray coatings. The article titled "Optimisation of the Machining of Stellite 6 PTA Hardfacing Using Surface Roughness" [2] deals with the machinability of a Stellite 6 thermal spray applied to a $100 \mathrm{~mm}$ diameter steel bar using the PTA method. The article focuses mainly on the roughness value Ra depending on the cutting speed, feed, and depth of cut. [2]

The parameters considered were the first cutting speed in a range $v_{c}=10-250 \mathrm{~m} / \mathrm{min}$ with a constant feed rate $f=0.1$ $\mathrm{mm} / \mathrm{rev}$ and depth of cut $\mathrm{a}_{\mathrm{p}}=0.5 \mathrm{~mm}$. It can be seen from Figure 1 that the best roughness values were obtained at cutting speeds of $80 \mathrm{~m} / \mathrm{min}$ and $125 \mathrm{~m} / \mathrm{min}$, at which a roughness of approximately $0.86 \mu \mathrm{m}$ was achieved. [2]
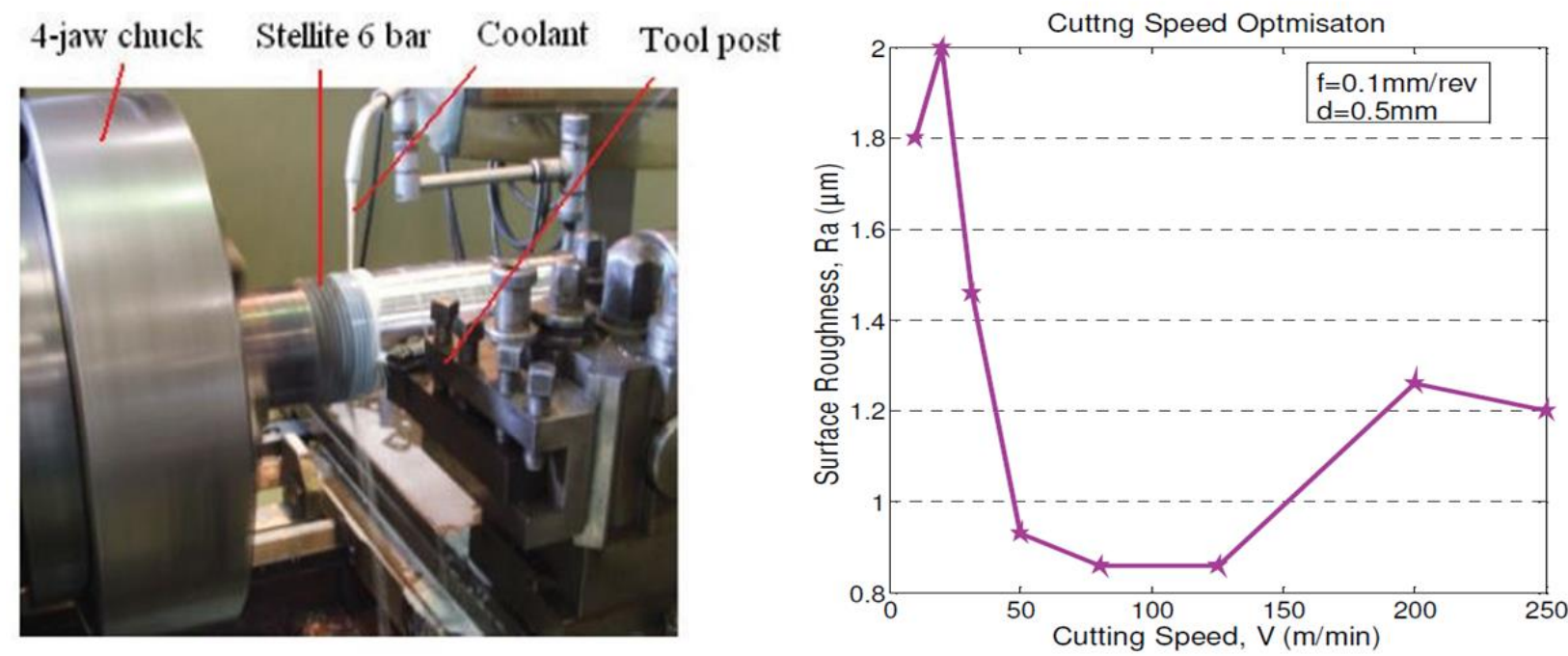

Fig. 1. Course of research experiment [2]

Graph 1. Dependence of cutting speed on parameter Ra [2]

In the second part, feed in the interval $\mathrm{f}=0.04-0.35 \mathrm{~mm} / \mathrm{rev}$ was examined. The constant cutting speed was set to $\mathrm{v}_{\mathrm{c}}$ $=80 \mathrm{~m} / \mathrm{min}$ according to the results of the previous experiment and the depth of cut remained unchanged $\mathrm{a}_{\mathrm{p}}=0.5 \mathrm{~mm}$. It can be seen from Figure 2 that the best roughness results in the range of $\mathrm{Ra}=0.6-1 \mu \mathrm{m}$ were achieved at lower feed rates up to $f=0.1 \mathrm{~mm} / \mathrm{rev}$. [2] In the latter case, the influence of the depth of cut in the range $a_{p}=0.08-1.4 \mathrm{~mm}$ was examined with a constant cutting speed $v_{c}=80 \mathrm{~m} / \mathrm{min}$ and a feed rate $\mathrm{f}=0.1 \mathrm{~mm} / \mathrm{rev}$. The graph 3 shows that as the depth of cut increases, the surface roughness deteriorates. [2]

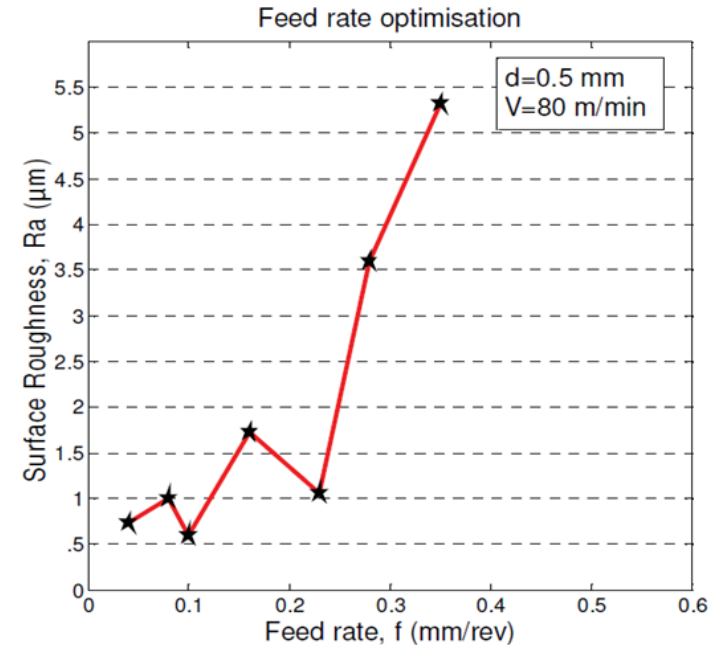

Graph 2. Feed rate dependence on Ra [2]

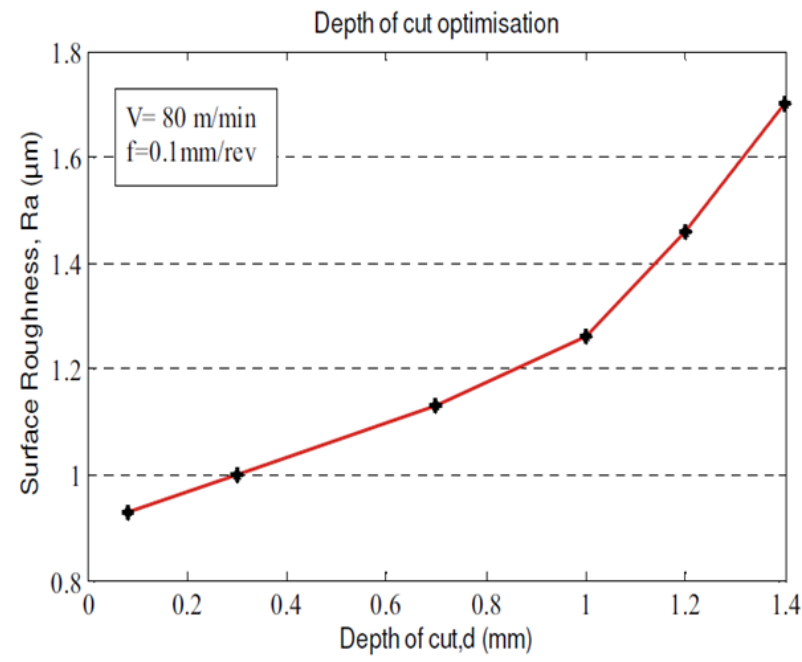

Graph 3. Dependence of the depth of cut on Ra [2] 


\section{Materials used and methodology of the experiment}

\subsection{Materials used}

The chromium-cobalt alloy Stellite 6 is primarily used in the form of coatings with a layer thickness of around 500 $\mu \mathrm{m}$. In the form of solid bulk materials, this alloy is not practically used for reasons of complicated manufacture and high cost of material. It gained its popularity mainly due to the balance between hardness and toughness. It contains a large amount of hard chromium and tungsten carbides, which contribute to a very good ability to withstand many kinds of wear, even at elevated temperatures. As the temperature rises, the alloy still maintains an appropriate hardness value of about $300-400 \mathrm{HV}$ up to $500^{\circ} \mathrm{C}$. [3]

\begin{tabular}{|c|c|c|c|c|c|c|c|c|c|}
\hline Co & Cr & W & C & Ni & Fe & Si & Mo & Mn & Other \\
\hline $45-60$ & $27-32$ & $4-6$ & $0,9-1,4$ & $\max .3$ & $\max$. & $\max$. & $\max .1$ & $\max .1$ & $\max .1$ \\
$\%$ & $\%$ & $\%$ & $\%$ & $\%$ & $3 \%$ & $1,5 \%$ & $\%$ & $\%$ & $\%$ \\
\hline
\end{tabular}

Table 1. Chemical composition of Stellite 6 [6]

Machinability can be understood as a technological property of a workpiece material that determines the severity of its machining under certain technological conditions. The machinability of the material depends on many factors. For example, chemical composition, physical and mechanical properties of the material being machined, cutting conditions, cutting tool geometry and material, working environment, etc. The chromium - cobalt alloy Stellite 6 is one of the heavy machinability materials due to a large amount of carbides mentioned, which cause intensive abrasion and blunting of the cutting edge. [4], [7]

\begin{tabular}{|c|c|c|c|c|c|}
\hline $\begin{array}{c}\text { Tensile strength } \\
\text { Rm [MPa] }\end{array}$ & $\begin{array}{c}\text { Yield strength Re } \\
{[\mathbf{M P a}]}\end{array}$ & $\begin{array}{c}\text { Ductility } \\
{[\%]}\end{array}$ & $\begin{array}{c}\text { Young's modulus of } \\
\text { elasticity [GPa] }\end{array}$ & $\begin{array}{c}\text { Hardness } \\
{[\mathbf{H V}]}\end{array}$ & $\begin{array}{c}\text { Micro hardness } \\
{\left[\mathbf{H V} \mathbf{V}_{\mathbf{0}, 3}\right]}\end{array}$ \\
\hline 850 & 700 & $<1$ & 209 & 410 & $650-700$ \\
\hline
\end{tabular}

Table 2. Mechanical Properties of Stellite 6 [6]

\subsection{Methodology of the experiment}

Strigon horizontal shaper with the designation GH560/U, which is located in the hall laboratories of UWB in Pilsen, was chosen for the experiment. The chosen technology was a simplified shaping process known as orthogonal cutting. The main condition for orthogonal cutting is that the cutting width is always greater than the width of the material being machined. For this reason, a 400 x $40 \mathrm{~mm}$ steel sheet with a width of $3 \mathrm{~mm}$ made of 11373 according to ČSN was chosen as a semi-finished product. This sheet was top coated with $500 \mu \mathrm{m}$ Stellite 6 thermal spray coating.

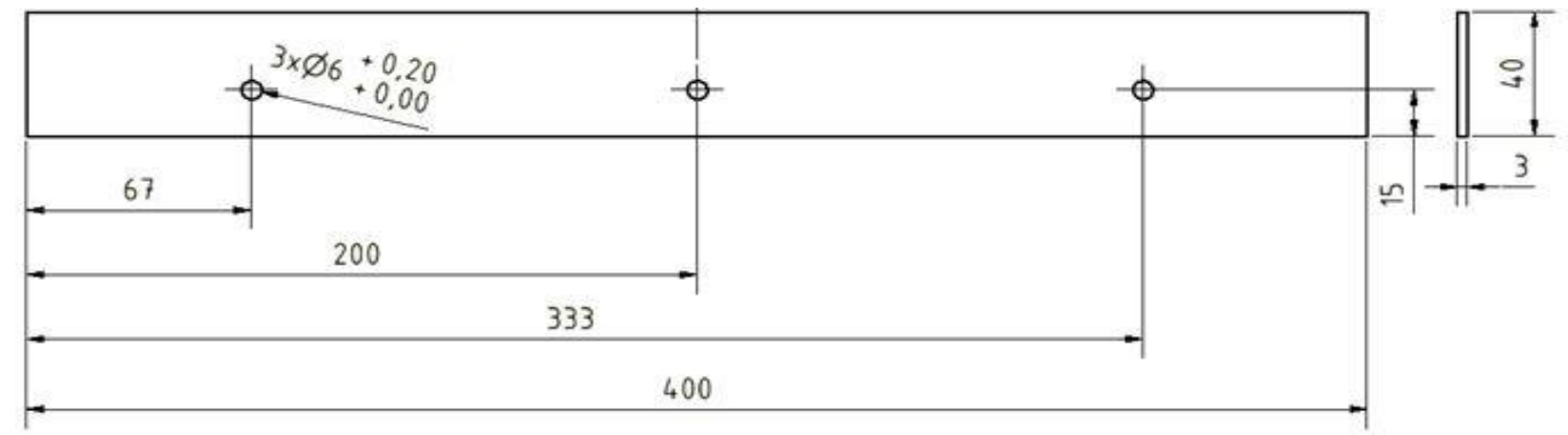

Fig. 2. Dimensions of the semi-finished product

In the experiment, we decided to vary the cutting speed in the range $\mathrm{v}_{\mathrm{c}}=20-55 \mathrm{~m} / \mathrm{min}$ in four steps and the cutting depth $\left(a_{p}\right)$ in two variants $(0.1$ and $0.3 \mathrm{~mm})$. The last variable was the setting of the rake angle at $\gamma=-7^{\circ}, 0^{\circ},+7^{\circ}$. 

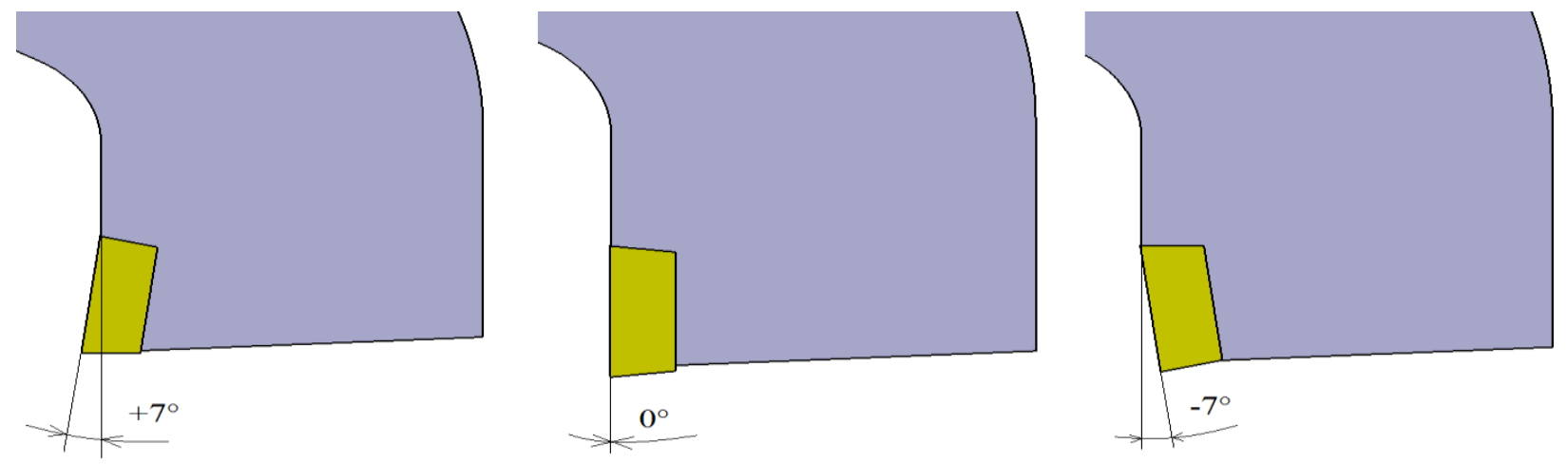

Fig. 3. Variants of cutting tool

As a cutting tool was chosen bending cutter made of chromium-molybdenum steel (42CrMo4) with strength 1000 MPa. This tool is clamped by Iscar's indexable insert SCMW 120408. It is an uncoated IC20 cemented carbide for roughing and finishing operations in aluminum, cast iron, and stainless steel.

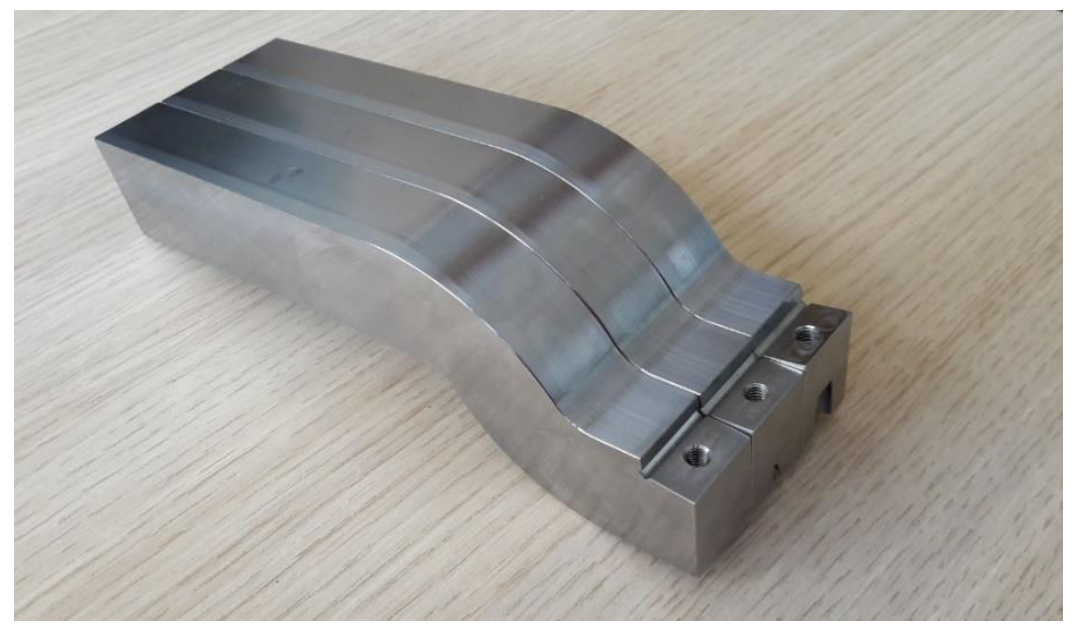

Fig. 4. Real resembles shaper blades

The whole process proceeded without any cooling and lubrication. A total of 24 Stellite 6 semi-finished parts were machined. In order to nullify the effect of wear, a new cutting edge was used for each semi-finished product. Initially, each semi-finished part was $0.1 \mathrm{~mm}$, which was used to align the surface of the thermal spray. Thereafter, the parameters selected by us varied in the following order (see Table 3 ).

\begin{tabular}{|c|c|c|c|}
\hline No. & vc [m/min] & $\gamma$ [ $\left.^{\circ}\right]$ & ap [mm] \\
\hline 14 & 43 & -7 & 0,3 \\
\hline 18 & 43 & 7 & 0,3 \\
\hline 23 & 55 & 7 & 0,1 \\
\hline 24 & 55 & 7 & 0,3 \\
\hline 19 & 55 & -7 & 0,1 \\
\hline 13 & 43 & -7 & 0,1 \\
\hline 22 & 55 & 0 & 0,3 \\
\hline 15 & 43 & 0 & 0,1 \\
\hline 20 & 55 & -7 & 0,3 \\
\hline 7 & 28 & -7 & 0,1 \\
\hline 21 & 55 & 0 & 0,1 \\
\hline 9 & 28 & 0 & 0,1 \\
\hline
\end{tabular}

\begin{tabular}{|c|c|c|c|}
\hline No. & vc [m/min] & $\gamma\left[^{\circ}\right]$ & ap [mm] \\
\hline 16 & 43 & 0 & 0,3 \\
\hline 10 & 28 & 0 & 0,3 \\
\hline 12 & 28 & 7 & 0,3 \\
\hline 8 & 28 & -7 & 0,3 \\
\hline 11 & 28 & 7 & 0,1 \\
\hline 5 & 20 & 7 & 0,1 \\
\hline 6 & 20 & 7 & 0,3 \\
\hline 1 & 20 & -7 & 0,1 \\
\hline 2 & 20 & -7 & 0,3 \\
\hline 4 & 20 & 0 & 0,3 \\
\hline 17 & 43 & 7 & 0,1 \\
\hline 3 & 20 & 0 & 0,1 \\
\hline
\end{tabular}

Table 3. Plan of the designed experiment

Each cut was recorded with the FASTCAM SA-X2 high - speed camera, which can be used to detect cutting edge behavior, chip formation, chip breaking, tool removal, etc. 


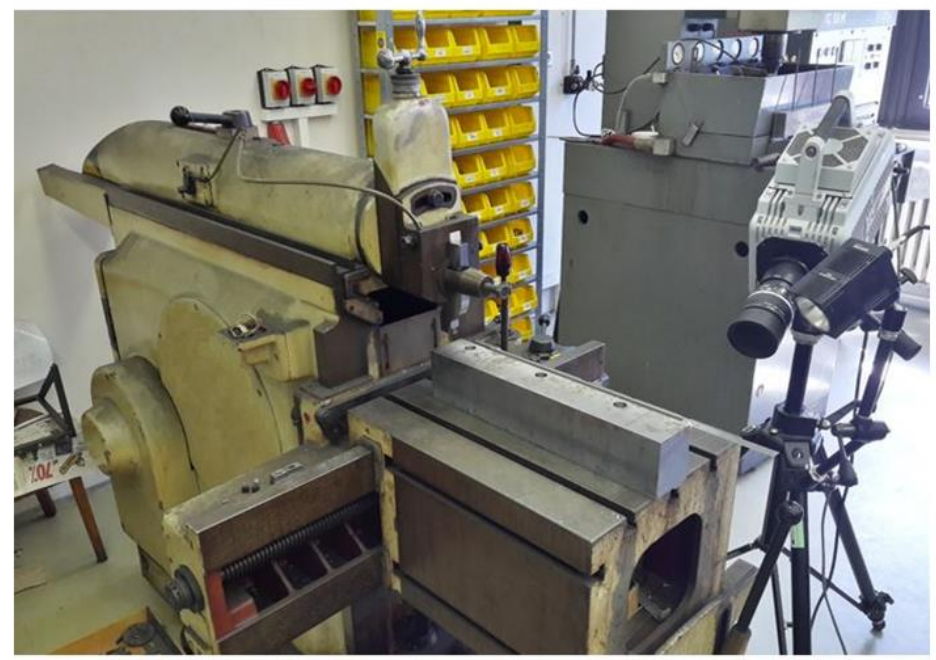

Fig. 5. Preparation of the experiment

\begin{tabular}{|l|l|}
\hline Machine & Strigon GH560/U \\
\hline Tool & Shaping tool \\
\hline Tool holder & Bent design \\
\hline Insert & SCMW 120408 \\
\hline Material of insert & Cemented carbide \\
\hline Cooling & No \\
\hline No. Of workpieces & 24 \\
\hline Thermal spray & Stellite 6 \\
\hline Cutting speed & $20,28,43,55 \mathrm{~m} / \mathrm{min}$ \\
\hline Cutting depth & 0.1 and $0.3 \mathrm{~mm}$ \\
\hline Face angle $\gamma$ & $-7^{\circ}, 0^{\circ},+7^{\circ}$ \\
\hline Lip angle $\beta$ & $90^{\circ}$ \\
\hline
\end{tabular}

Table 4. Summary of the experiment plan

\section{Materials used and methodology of the experiment}

\subsection{Materials used}

After reviewing the records for chip formation, several differences were observed. In most cases, significant changes in chip exits from the cut point cannot be seen, even though the measured surface roughness Ra is very different. It was often a helical fragments chip, which is mainly due to the process used (orthogonal cutting). The chip usually went smoothly from the cutting point at the angle of the face. The first recorded change of chip formation was at workpiece No. 8, where the chip changed from a helical fragments chip to an elementary chip. In Figures 6 and 7, the difference in chip shape can be seen as a function of the depth of cut at the same cutting speed and rake angle.

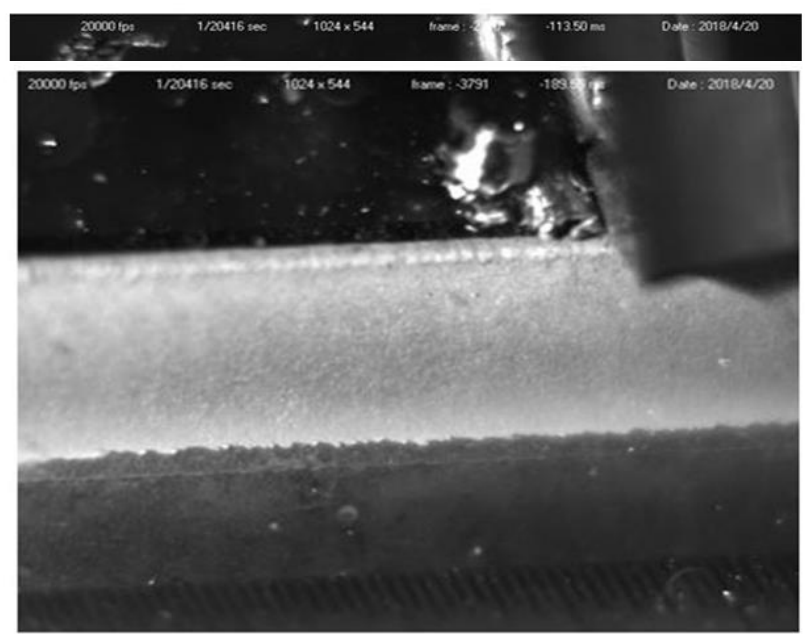

Fig. 6. Chip formation on No. $7\left(a_{p}=0.1 \mathrm{~mm}\right)$

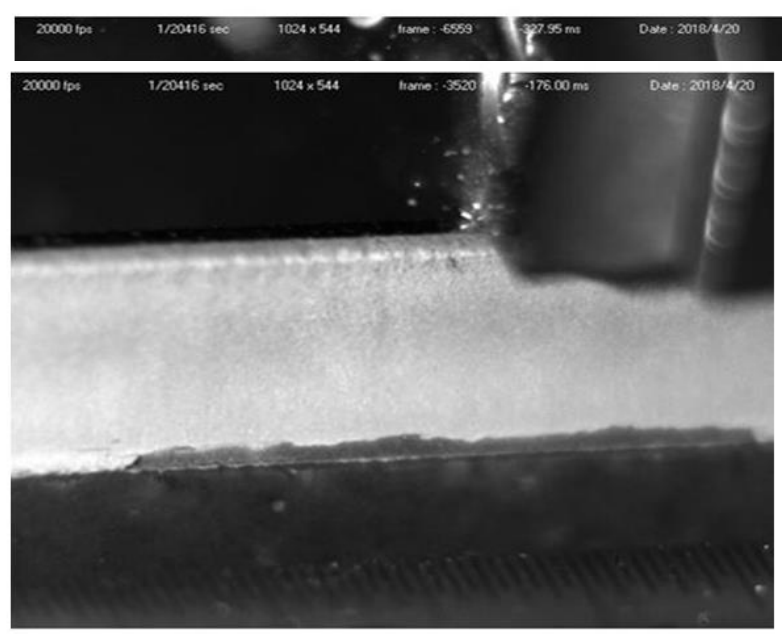

Fig. 7. Chip formation on No. $8\left(a_{p}=0.3 \mathrm{~mm}\right)$

Fig. 9. Chip formation on workpiece No. 23

Fig. 8. Chip formation on workpiece No. 14

For workpiece no. 14 (Fig. 8), chip accumulation was observed in front of the cutting edge, which could be due to the negative slope of the insert face and greater depth of cut ap $=0.3 \mathrm{~mm}$.

The last recorded difference concerned workpieces no. 18, 23, 24. The machining of these workpieces did not remove the required depth of cut. The workpieces listed have a common rake angle $\gamma=+7^{\circ}$ and a higher cutting speed $\mathrm{v}_{\mathrm{c}}=43$ and $55 \mathrm{~m} / \mathrm{min}$. Under these conditions, the tool may have been pushed off because of contact with the thermal spray, see Figure 9.

\subsection{Evaluation of the Ra parameter}

The roughness parameter Ra was measured on a Hommel Etamic T8000 according to DIN EN ISO 4288 : 1998 norm. From the measured values it was found that very good roughness $\mathrm{Ra} \leq 0.8 \mu \mathrm{m}$ was achieved in several workpieces with 
different combinations of cutting depth, cutting speed and rake angle. The best result was achieved with workpiece No. 11 and No. 17 with a roughness value $\mathrm{Ra}=0.25 \mu \mathrm{m}$. A statistical evaluation was then made from the measured roughness.

Statistical evaluation is a method based on data analysis, which enables to evaluate obtained information about the whole and its parts. For our experiment, which was designed by the methodology of the planned experiment, the ANOVA method was used. Using statistical evaluation, we determined the effects of individual factors and their interactions in dependence on the roughness parameter Ra.

One of the first steps is to determine the significance of the model of the parameter Ra under investigation. The aim is to achieve a significance level ( $\mathrm{p}$ ) below 5\%. It can then be concluded that the observed variable Ra is dependent on changing levels of factors. Thus, there is at least one factor that significantly affects the change in the roughness value Ra.

\begin{tabular}{|c|c|c|c|c|c|c|c|c|c|c|c|}
\hline \multirow{2}{*}{$\begin{array}{c}\text { Dependent } \\
\text { Variable }\end{array}$} & \multicolumn{10}{|c|}{ Test of SS Whole Model vs. SS Residual } \\
\cline { 2 - 12 } & $\begin{array}{c}\text { Multiple } \\
\text { R }\end{array}$ & $\begin{array}{c}\text { Multiple } \\
\text { R2 }\end{array}$ & $\begin{array}{c}\text { Adjusted } \\
\text { R2 }\end{array}$ & $\begin{array}{c}\text { SS } \\
\text { Model }\end{array}$ & $\begin{array}{c}\text { Df } \\
\text { Model }\end{array}$ & $\begin{array}{c}\text { MS } \\
\text { Model }\end{array}$ & $\begin{array}{c}\text { SS } \\
\text { Residual }\end{array}$ & $\begin{array}{c}\text { Df } \\
\text { Residual }\end{array}$ & $\begin{array}{c}\text { MS } \\
\text { Residual }\end{array}$ & F & p \\
\hline $\mathrm{Ra}$ & 0.636703 & 0.405390 & 0.308397 & 23.33892 & 23 & 1.014736 & 34.23260 & 141 & 0.242784 & 4.179576 & 0.0000 \\
\hline
\end{tabular}

Table 5. Table of the significance of the model of the studied parameter Ra

\begin{tabular}{|l|c|c|c|c|c|}
\hline \multirow{2}{*}{ Effect } & \multicolumn{6}{|c|}{ Univariate Tests of Significance for Ra - Sigma - restricted parameterization } \\
Effective hypothesis decomposition
\end{tabular}

Table 6. The influence of individual factors on the roughness parameter $\mathrm{Ra}$

Tab. 6 shows that the parameter Ra is significantly influenced by changing the rake angle, cutting speed - rake angle interaction, cutting speed - cutting depth interaction, and cutting speed, rake angle and cutting depth interaction. The graphs below represent the individual dependencies of the Ra parameter on the change in rake angle, cutting speed and depth of cut.

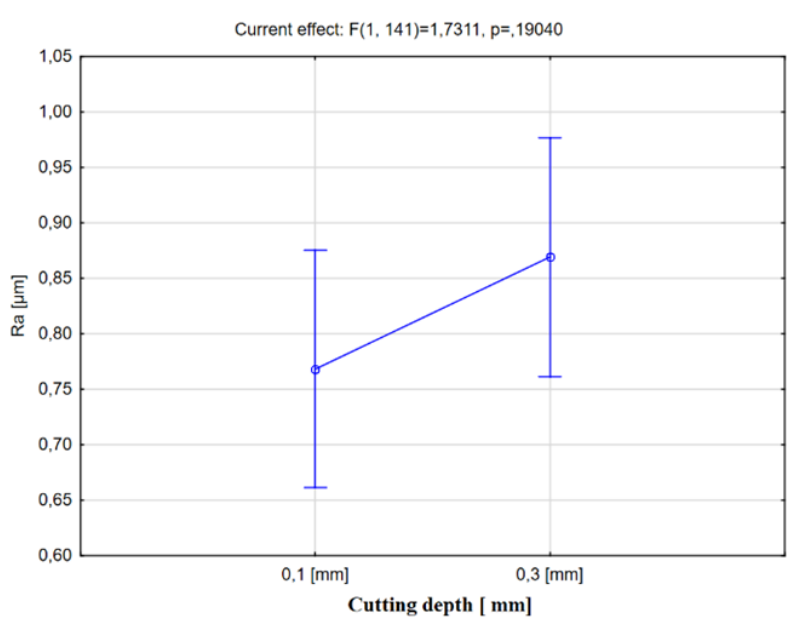

Graph 4. Dependence of rake angle on the parameter Ra

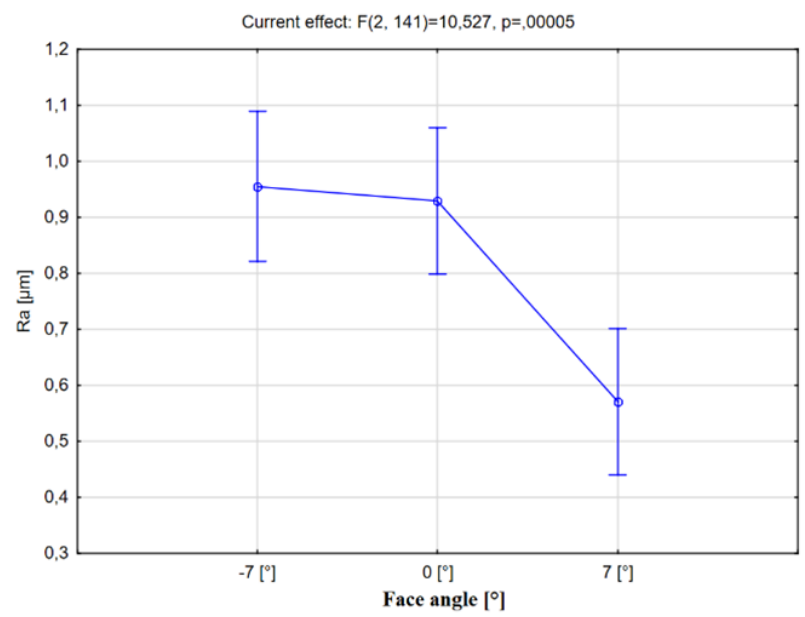

Graph 5. Dependence of cut depth on the parameter Ra 


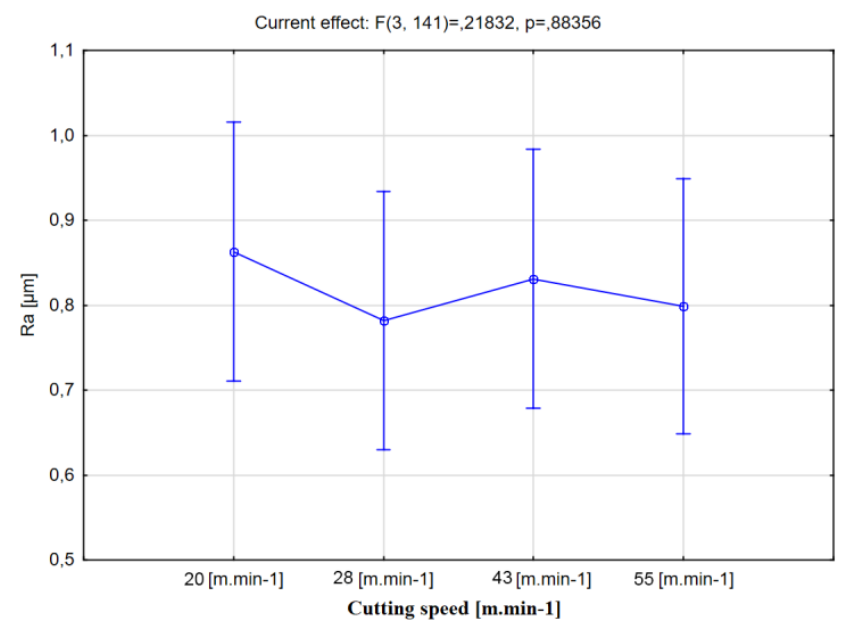

Graph 6. Dependence of cutting speed on the parameter Ra

From the above graphs it is possible to find out how the surface roughness was influenced when changing the settings of varied parameters. In the case of cutting speed, the surface roughness increases with increasing cutting speed, confirming the theoretical assumptions. The depth of cut from the above graph is much better for the variant $a_{p}=0.1 \mathrm{~mm}$. With the rake angle adjustment, it was expected from previous searches that better results would be obtained with a rake angle adjustment $\gamma=-7^{\circ}$. Graph 4 , however, shows exactly the opposite result.
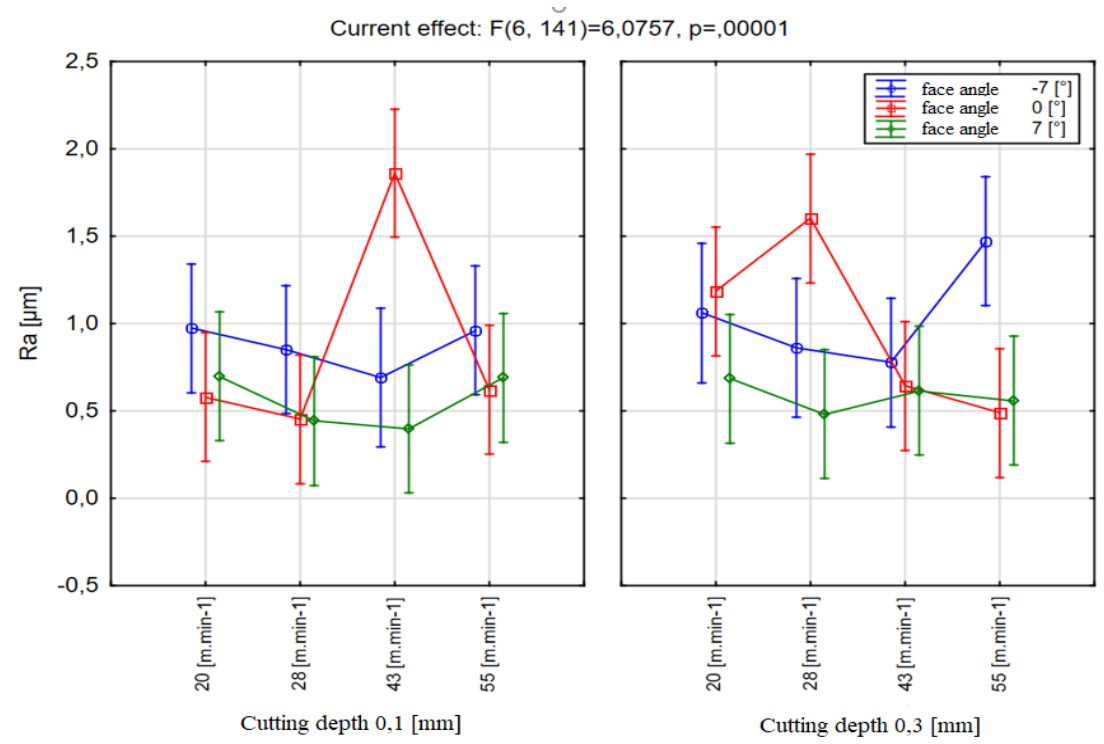

Graph 7. Dependence of rake angle, depth of cut and cutting speed on the parameter Ra

\section{Conclusion}

This work dealt with machinability thermal spray Stellite 6. The main objective of this work was to replace the grinding technology for more productive machining technology with defined cutting geometry. The main advantage of this change is the shortening of production times and thus the increase of productivity and also the change of residual stresses from tensile to compressive.

The experiment took place on a Strigon horizontal shaper. The chosen technology was a simplified shaping process known as orthogonal cutting. In the experiment, we decided to vary the cutting speed $\left(\mathrm{v}_{\mathrm{c}}=20-55 \mathrm{~m} / \mathrm{min}\right)$, the cutting $\operatorname{depth}\left(\mathrm{a}_{\mathrm{p}}=0.1\right.$ and $\left.0.3 \mathrm{~mm}\right)$ and the rake angle setting $\left(\gamma=-7^{\circ}, 0^{\circ},+7^{\circ}\right)$. A total of 24 semi-finished products with Stellite 6 were machined under various varied conditions. In order to nullify the effect of wear, a new cutting edge for the insert was used for each workpiece.

For a better understanding of how chip formation was made, each cut was recorded on a high speed camera. From the obtained shots we revealed that in most cases it was a helical fragments chip even with significantly different roughness values. In some cases, especially in the variant with a negative rake angle, the chip unusually accumulated in front of the cutting edge. For the semi-finished products numbers 18, 23 and 24, the specified depth of cut was not removed due to the pushing of the shaping knife. 
From the measured roughness values Ra, it was found that very good roughness $\mathrm{Ra} \leq 0.8 \mu \mathrm{m}$ was achieved in several workpieces. The best result was achieved with workpiece No. 11 and No. 17 with a roughness value $\mathrm{Ra}=0.25 \mu \mathrm{m}$. From the measured roughness values, a statistical evaluation was created to determine the effects of individual factors and their interactions. The graphs show that better results can be obtained with a smaller depth of cut $\left(\mathrm{a}_{\mathrm{p}}=0.1 \mathrm{~mm}\right)$, a positive rake adjustment $\left(\gamma=+7^{\circ}\right)$ and a mean cutting speed $\left(\mathrm{v}_{\mathrm{c}}=28\right.$ and $\left.43 \mathrm{~m} / \mathrm{min}\right)$.

In conclusion, the experiment performed and its evaluation was beneficial because we managed to some extent replace the grinding technology with a more productive shaping technology. It should be stressed, that this was achieved with a very simplified orthogonal cutting process.

Since the Stellite 6 thermal spraying process has not yet been published by another organization, we are not able to compare our results with shaping technology. However, when compared to turning technology, it has been confirmed that better results can be obtained at higher cutting speeds and using a smaller cutting depth. On the other hand with the rake angle adjustment, it was expected from previous searches that better results would be obtained with a rake angle adjustment $\gamma=-7^{\circ}$. Graph 4, however, shows exactly the opposite result.

\section{Acknowledgments}

This article was created under the project SGS-2019-008: Research and Development for Innovation in the Field of Manufacturing Technology - Machining Technology III.

\section{References}

[1] Hoesel, D.; Wertheim, R.; Haenel, T. \& Thurner, S. (2011). Milling of Cast Material and PTA-Hard-Facing Layers of the Cobalt-Base-Alloy Stellite 12, Annals of DAAAM for 2011 \& Proceedings of the 22th International DAAAM Symposium, Published by DAAAM International, Vienna, 2011, ISBN 978-3-901509-83-4

[2] Hasan, M. S.; Abdul M. M. \& Clegg, R. E. (2010). Optimisation of the Machining of Stellite 6 PTA Hardfacing Using Surface Roughness. Key Engineering Materials. DOI: 10.4028/www.scientific.net/KEM.443.227.

[3] www.stellite.com, (2019). Kennametal Stellite. Hardfacing Alloys. Accessed on: 2018-03-03. Available from: http://www.stellite.com/content/dam/kennametal/stellite/literature/Brochures/B-1605107_KMT_Stellite_Hardfacing Alloys_Brochure_EN_LR.pdf

[4] Zaman, H. A.; Sharif, S.; Kim, D. W.; Idris, M. H.; Suhaimi, M. A. \& Tumurkhuyag, Z. (2017). Machinability of Cobalt-based and Cobalt Chromium Molybdenum Alloys - A Review, Procedia Manufacturing, Volume 11, Pages 563-570, ISSN 2351-9789, https://doi.org/10.1016/j.promfg.2017.07.150.

[5] Yingfei G.; Muñoz, P. \& Galloway, A. (2017). Influence of Cutting Parameters and Tool Wear on the Surface Integrity of Cobalt-Based Stellite 6 Alloy When Machined Under a Dry Cutting Environment. Journal of Materials Engineering and Performance (2017) 312-326, DOI: 10.1007/s11665-016-2438-0.

[6] www.exocor.com (2017). Technical publications. Accessed on: 2018-03-03. Available from: http://exocor.com/downloads/product-datasheets/Stellite-6-Datasheet.pdf

[7] Řehoř, J. Theory of Machining. ZČU v Plzni [Internal documentation]. Available from: 2018-03-03

[8] www.mmspektrum.com, (2005). MM Industrial Spectrum. Innovation - Surface treatment. Accessed on: 2018-0303. Available from: http://www.mmspektrum.com /clanek/zarove-strikane-povlaky-moderni-technologie-tvorbypovrchovych-ochra.html

[9] Hajdarevic, D. B.; Cekic, A. \& Kulenovic, M. (2014). Experimental Study on the High Speed Machining of Hardened Steel, Annals of DAAAM for 2014 \& Proceedings of the 25th International DAAAM Symposium, Published by DAAAM International, Vienna, 2014, pp. $291-295$.

[10] Ozturk, S. (2014) Machinability of Stellite-6 Coatings with Ceramic Inserts and Tungsten Carbide Tools. Arabian Journal for Science and Engineering DOI: 10.1007/s13369-014-1343-9.

[11] Farsky, J.; Baksa, T. \& Zetek, M. (2018).Influence of Grinding Parameters on Forces when Grinding Maraging Steel X3Nicomo 1895 with SiC Grinding Wheels; Proceedings of the 29th International DAAAM Symposium 2018. DAAAM International Vienna, 2018, s. 0767-0771. DOI: 10.2507/29th.daaam.proceedings.111. 